\title{
O esgotamento do fordismo e o neoliberalismo como "fuga para frente" do capital de sua crise estrutural.
}

\author{
The exhaustion of fordism and neoliberalism \\ as a "forward scape" of capital from its structural crisis
}

Remo Moreira Brito Bastos Mestrando em educação pela UFC remomoreira@gmail.com

\begin{abstract}
Resumo: O presente texto busca recuperar os nexos causais e as condições históricas que desencadearam o aparecimento do neoliberalismo, ordem social por meio da qual os capitalistas empreenderam a recuperação da hegemonia econômica, social, política e cultural nas sociedades de capitalismo avançado e a neocolonização das nações periféricas. Impossibilitado de enfrentar as raízes de suas inexoráveis crises, o sistema sociometabólico do capital opta, após a Segunda Grande Guerra, pela estratégia da "fuga para frente", de modo a dar sobrevida a suas cíclicas fases de expansão da acumulação de capital. Faz isso deslocando espacial e temporalmente aquelas contradições, consubstanciando um padrão de acumulação que ficou conhecido como fordismo, cujo esgotamento, a partir de meados da década de 1960, passa a comprometer seriamente a acumulação de capital nos países de capitalismo avançado, deflagrando uma crise cuja natureza estrutural, inédita, ameaça a própria existência do sistema.
\end{abstract}

Palavras-chave: Capitalismo. Fordismo. Keynesianismo. Neoliberalismo. Crise estrutural do capital.

\begin{abstract}
This text aims to retrieve the causal nexuses and the historical conditions that triggered the rise of neoliberalism, a social order through which the capitalists achieved to accomplish the economic, social, political and cultural hegemony in advanced capitalists societies, as well as the neo-colonization of the peripheral nations. Incapable of facing the roots of its inexorable crises, the social metabolic capital system opts, after the Second World War, for the "forward flee", in order to lengthen the cyclical expansion phases of capital accumulation. It does so by temporally and spatially displacing its immanent contradictions forward, materializing an accumulation pattern which came to be well-known as fordism, whose exhaustion, since the mid 1960s, starts to undermine the capital accumulation in the advanced capitalist countries, activating a crisis whose nature, unprecedented, threatens considerably the existence of the system itself.
\end{abstract}

Keywords: Capitalism. Fordism. Keynesianism. Neoliberalism. Structural capital crisis

Originais recebidos em: 05/05/2014

Aceito para publicação em: 17/07/2014

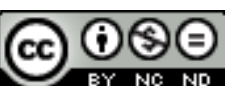

Este trabalho está licenciado sob uma Licença Creative Commons Atribuição-Uso NãoComercial-Vedada a criação de obras derivadas 3.0 Unported License. 


\section{Introdução}

Neste artigo, composto de um preâmbulo e três seções, tratar-se-á de analisar a natureza e o modus operandi do processo por meio do qual os capitalistas reestruturaram a produção, de forma a vencer os constrangimentos que, a partir de meados da década de 1960, começaram a minar a acumulação de capital nos países de capitalismo avançado, processo que passa a conformar um corpo teórico e empírico político-econômico que impõe, como valores fundamentais, a defesa incondicional da propriedade privada e a liberdade de mercado.

Esse corpo teórico e empírico ficou conhecido como neoliberalismo, e vem hegemonizando, desde então, em âmbito mundial, não apenas a esfera econômica, mas diversas outras, como a social, a política e a cultural, consubstanciando uma poderosa ferramenta ideológica a serviço do capital no intuito de obter o consentimento necessário para as medidas que possam potencializar a recuperação do dinamismo da acumulação do capital nas economias dos países centrais.

Na primeira seção, busca-se sucintamente conceptualizar e traçar o percurso histórico do neoliberalismo, bem como apreender seus determinantes ideológicos e seus vínculos de classe.

Na segunda, procede-se a uma caracterização da crise estrutural do capital, buscandose apreender os nexos histórico-econômicos, sociais e políticos que delinearam sua irrupção, em meados da década de 1960 e início da década seguinte.

$\mathrm{Na}$ terceira, contempla-se o esgotamento do fordismo, o qual não mais consegue deslocar paliativamente as contradições do modo capitalista de produção, deflagrando a emergência da crise estrutural do capital.

\section{O neoliberalismo como "fuga para frente" do capital de sua crise estrutural}

Como forma de se desvencilhar de suas contradições imanentes, as quais se manifestam de forma cada vez mais intensa e desestabilizadora, das quais não poderá jamais se livrar definitivamente, o capital busca atenuar os efeitos dessas contradições, tentando deslocá-las "para frente" temporal e espacialmente, procrastinando, assim, "a hora da verdade" do enfrentamento de suas contradições fundamentais, como se verá no presente artigo. 


\section{Conceito, gênese, evolução histórica e essência ideológica do neoliberalismo}

Em 1947, o economista Friedrich Hayek organizou uma conferência na Suíça, em um vilarejo próximo aos Alpes chamado Mont Pèlerin. Participaram importantes intelectuais conservadores, pró-capital, como Milton Friedman, Karl Popper e Ludwig von Mises, dentre outros. Na ocasião, deu-se a fundação da agremiação que tomou emprestado seu nome da localidade do evento (Sociedade Mont Pèlerin), considerada o germe da revitalização do liberalismo econômico, desacreditado com a Grande Depressão de 1929-34, e cujo ideário permaneceu no limbo por mais de quarenta anos, ofuscado pela hegemonia do keynesianismo. Ao cabo desse período, o liberalismo retoma do keynesianismo o posto de escola do mainstream econômico, aproximadamente no início dos anos 1970, com o agravamento dos sintomas da crise estrutural do capital, cujas primeiras manifestações mais explícitas, conforme se viu, datam de meados da década de 1960, mas se agudizaram com a "crise do petróleo" de 1973-74.

A obra seminal que serviu de referencial teórico para essa articulação político-ideológica havia sido escrita há aproximadamente trinta anos (em 1944): O Caminho da Servidão, de Friedrich Hayek. Nela o autor desfere pesados ataques à limitação dos poderes do mercado por parte do Estado, assim como contra o poder da classe trabalhadora, a quem acusa pela destruição dos níveis indispensáveis de lucros do setor privado, o que teria sido a causa principal dos surtos inflacionários que levaram à crise dos anos 1970. Prescreve, então, o remédio neoliberal: um Estado forte para conter o poder dos sindicatos e exercer o rígido controle da política monetária, mas omisso com relação aos gastos sociais e às políticas macroeconômicas anticíclicas. Nas palavras de Hayek (2010, p. 193): "Foi a submissão às forças impessoais do mercado que possibilitou o progresso de uma civilização que, sem isso,

não se teria desenvolvido. É, portanto, submetendo-nos que ajudamos dia a dia a construir algo cuja magnitude supera a nossa compreensão".

Pode-se conceituar o neoliberalismo como uma doutrina de dominação engendrada em benefício dos interesses do grande capital, notadamente o financeiro, que se exprime nas dimensões social, ideológica, política e econômica, com predomínio desta. Oriunda dos postulados fundamentais do liberalismo clássico, revisa e readapta esses às características e aos determinantes funcionais do capitalismo em seu atual estágio de desenvolvimento, marcado pela exacerbação das políticas nacionais de abertura e desregulamentação de 
mercados e pela hegemonia do capital fictício, como alternativa à acentuada queda das oportunidades de extração de mais-valia na esfera produtiva.

Como uma doutrina econômica, seu "oráculo" é o mercado, que subordina não somente a todos os atores econômicos de sua esfera, mas a quase todas as demais dimensões da vida humana em sociedade, que têm sua reprodução e sua regulação determinadas pelos imperativos ditados por aquele, o qual rechaça qualquer intervenção limitativa ao seu desregrado funcionamento. Portanto, a liberdade de mercado constitui um axioma e um valor fundamental intrinsecamente inalienáveis ao neoliberalismo.

Enquanto doutrina filosófica, esse ideário busca suas bases de fundamentação na filosofia moral, mais precisamente nas concepções de liberdade absoluta do homem e de sua predominância sobre a dimensão social e coletiva, engendrando um individualismo que constitui apanágio de sua configuração ideológica e filosófica. No campo da política, tem como valor basilar a competição, tanto de indivíduos quanto de nações, em um ambiente socioeconômico internacional que, hodiernamente, convencionou-se qualificar de "globalizado".

Na próxima seção, tratar-se-á de analisar a natureza e o modus operandi do processo por meio do qual os capitalistas reestruturaram a produção, de forma a vencer os constrangimentos que, a partir de meados da década de 1960, começaram a minar a acumulação de capital nos países de capitalismo avançado.

\section{Caracterização da crise estrutural do capital ${ }^{1}$}

A história do capitalismo tem sido, desde que se consolidou o comando do capital sobre a produção social nos países economicamente dominantes, uma sucessão de crises de duração e intensidade diversas, evidenciando, assim, o caráter intrinsecamente instável da dinâmica desse modo de reprodução sociometabólico. Há que se considerar, igualmente, que

\footnotetext{
${ }^{1}$ A análise que se pretende empreender na presente seção funda-se na perspectiva crítica de Istvam Mészáros (2000, 2011a, 2011b). Importa observar que a concepção de crise estrutural desse autor não tem aceitação unânime no seio marxista, sendo considerada exagerada ou mesmo catastrofista por muitos que a ela se opõem. $\mathrm{O}$ autor do presente artigo pondera os argumentos das duas posições, mas reserva-se o direito de aliar-se a Mészáros, por constatar que este nunca, em sua obra, procurou vaticinar o colapso do sistema do capital (o mesmo podendo-se afirmar de Marx, que foi injustamente acusado da mesma conduta), mas buscou, notadamente em sua obra de maior envergadura (2011b), proceder a uma atualização categorial de $O$ Capital, preservando os fundamentos básicos da teoria do valor e da dialética da luta de classes imanentes ao referencial marxiano. Naquela obra, Mészáros pontua que o capital aproxima-se de seus limites históricos, até pelo fato de que o processo de sua valorização encontra cada vez mais obstáculos, o que o faz refugiar-se cada vez mais na ilusória esfera especulativa que, sabe-se, cedo ou tarde, cobra o preço de seus desvarios. Ou seja, pode o capital continuar a, por algum tempo, deslocar suas inarredáveis contradições, mas mesmo essa alternativa cobra seus
} 
o caráter imanentemente antagônico do capital em relação ao trabalho acarreta que a crise seja constitutiva do próprio sistema, ou seja, o capitalismo simplesmente não pode existir sem crises, as quais, na verdade, constituem a manifestação fenomênica de suas inarredáveis contradições. Em outras palavras, a absoluta necessidade de expansão, orientada pela acumulação do capital, faz com que esse imponha sua lógica cruel e irracional sobre a sociedade, independentemente do caráter devastador de suas consequências. Isso ocorre porque essa expansão não se dá em congruência com as necessidades humanas, contudo tem como móvel a própria acumulação de capital, como um fim em si mesma, de forma a atender uma necessidade vital intrínseca de sobrevivência do seu sistema.

Tais crises, que inicialmente eram circunscritas àqueles países, evoluíram, na contemporaneidade, para uma crise estrutural de alcance geográfico global, que afeta todos os ramos de produção e, até mesmo, todas as esferas de vida da população mundial. Nas palavras de Mészáros:

Em termos simples e gerais, uma crise estrutural afeta a totalidade de um complexo social em todas as relações com suas partes constituintes ou sub-complexos, como também a outros complexos aos quais é articulada. Diferentemente, uma crise não estrutural afeta apenas algumas partes do complexo em questão, e assim, não importa o grau de severidade em relação às partes afetadas, não pode pôr em risco a sobrevivência contínua da estrutura global. Sendo assim, o deslocamento das contradições só é possível enquanto a crise for parcial, relativa e interiormente manejável pelo sistema, demandando apenas mudanças - mesmo que importantes no interior do próprio sistema relativamente autônomo. Justamente por isso, uma crise estrutural põe em questão a própria existência do complexo global envolvido, postulando sua transcendência e sua substituição por algum complexo alternativo. (MÉSZÁROS, 2011b, p. 796-797, grifo do autor).

Ao afirmar que "o deslocamento das contradições só é possível enquanto a crise for parcial, relativa e interiormente manejável pelo sistema [...] no interior do próprio sistema relativamente autônomo", Mészáros remete-se às estratégias reformistas da social-democracia dos "trinta anos gloriosos", quando a afluência encontrada nas sociedades dos países centrais, obtida à custa da cruenta superexploração ${ }^{2}$ dos trabalhadores dos países subdesenvolvidos, obscurecia que a "ajuda estranha" 3 do Estado atuava meramente deslocando internamente ao subsistema as contradições existentes e ajustando-as da maneira possível de forma a

\footnotetext{
cada vez mais incontornáveis custos humanos, sociais e ambientais.

${ }^{2}$ Categoria analítica fundamental da Teoria Marxista da Dependência. Tendo em vista a limitação de escopo do presente trabalho, pode-se defini-la, para efeito de compreensão do trecho objeto da presente nota, grosso modo, como o pagamento da força de trabalho abaixo de seu valor.

${ }^{3}$ Com essa expressão, sempre entre aspas, Mészáros $(2011$ b) refere-se à intervenção de um elemento externo ao sistema metabólico do capital (o Estado), no sentido de remover (ou deslocar) obstruções que impedem a continuidade de seu ciclo de reprodução, que pode ser esquematicamente expresso pela fórmula $M^{\prime}--D^{\prime}--M \ldots P$ . . . $M^{\prime}$, na qual $P$ representa a produção, $M$ a mercadoria, $M^{\prime}$ a mesma, prenhe de mais-valia, $D$ o dinheiro, e seu montante acrescido $D^{\prime}$, sendo o processo de circulação apresentado em hifens (---) e o de produção em pontos (...), ambos necessariamente assincrônicos um em relação ao outro.
}

Em Debat: Rev. Dig., ISSNe 1980-3532, Florianópolis, n. 10, p. 105-120, jul-dez, 2013. 
compatibilizá-las aos imperativos do processo de acumulação de capital, como sintetiza Mészáros:

\begin{abstract}
Em outras palavras, contradições parciais e 'disfunções', ainda que severas em si mesmas, podem ser deslocadas e tornadas difusas - dentro dos limites últimos ou estruturais do sistema - e neutralizadas, assimiladas, anuladas pelas forças ou tendências contrárias, ${ }^{4}$ que podem até mesmo ser transformadas em força que ativamente sustenta o sistema em questão. Daí o problema da acomodação reformista. (MÉSZÁROS, 2011b, p. 797). ${ }^{5}$
\end{abstract}

Essas manobras protelatórias, na tentativa de resolver a crise fundamental, ainda dispunham de algum fôlego e iludiam a classe trabalhadora dos países centrais, embebida nas benesses do pacto "capital-trabalho" então vigente naqueles países, conforme será exposto no próximo tópico.

No que se refere à dimensão temporal, a crise não mais se manifesta de acordo com um padrão cíclico, à medida que as crises que emergiram após 1973 (a "crise da dívida" dos países latino-americanos da década de 1980, as crises financeiras da década de 1990 na Ásia, no Brasil, no México, na Rússia, em 2001, na Argentina, etc.) não passam de manifestações epifenomênicas da crise estrutural deflagrada em meados da década de 1960, que se estende até o momento atual, consoante se verá na sequência da presente exposição. Da mesma forma, como bem salienta o filósofo húngaro:

Em contraste com as erupções e os colapsos mais espetaculares e dramáticos do passado, seu modo de se desdobrar poderia ser chamado de rastejante, desde que acrescentemos a ressalva de que nem sequer as convulsões mais veementes ou violentas poderiam ser excluídas no que se refere ao futuro: a saber, quando a complexa maquinaria agora ativamente empenhada na 'administração da crise' e no 'deslocamento' mais ou menos temporário das crescentes contradições perder sua energia. (MÉSZÁROS, 2011b, p. 796, grifo do autor).

Inobstante o controle absoluto que exerce sobre a produção social nos países economicamente hegemônicos e em muitos países periféricos, o capital não conseguiu se consolidar universalmente, em sua forma propriamente capitalista, tendo de aceitar, em diversas circunstâncias, a hibridização do sistema, necessitando, de forma vital, da "ajuda estranha" do Estado, no sentido de deslocar "para frente", nas dimensões de tempo e espaço, suas contradições imanentes, já que estas são constitutivamente insolúveis. A própria necessidade de "ajuda estranha" já denota forte indício da debilidade constitutiva do sistema

\footnotetext{
${ }^{4}$ Tais tendências podem enquadrar-se nas contratendências à lei tendencial da queda da taxa de lucro, aludidas por Marx (2008, p. 307), a saber: aumento do grau de exploração do trabalho, a redução dos salários abaixo de seu valor, a baixa de preço dos elementos do capital constante, a "superpopulação relativa" (o exército de reserva de mão de obra permite iniciar novos negócios com menor composição orgânica de capital, elevando, assim, a taxa média de lucro), e o comércio exterior (acesso a matérias-primas e alimentos mais baratos, provenientes de países periféricos, de economia primária, barateando assim o capital constante e aumentando a taxa de maisvalia).

${ }^{5}$ A responsabilidade pelas traduções, assim como pelo emprego dos grifos e dos colchetes, esses quando não

Em Debat: Rev. Dig., ISSNe 1980-3532, Florianópolis, n. 10, p. 105-120, jul-dez, 2013.
} 
do capital, indicando, assim, que "algo diferente da normalidade da extração e apropriação do sobre-trabalho pelo capital tinha que ser introduzido para conter as disfunções do sistema" (MÉSZÁROS, 2000, p. 14). Alerta o estudioso húngaro, contudo, que “[...] Não obstante, as disfunções de cada uma, consideradas separadamente, devem ser distinguidas da crise fundamental do todo, que consiste no bloqueio sistemático das partes constituintes vitais." (MÉSZÁROS, 2011b, p. 798). Dessa forma, há que se prevenir da aparência de uma crise estrutural, que pode ocorrer quando um bloqueio temporário de um dos canais internos pode emperrar provisoriamente o sistema, armadilha na qual caiu Stalin, julgando ser a crise de 1929-33 terminal para o MCP (modo capitalista de produção).

Mészáros aponta para uma contemporânea coexistência problemática entre as três dimensões fundamentais do capital, a saber, produção, consumo e circulação/realização. Essas, no curso do desenvolvimento histórico do sistema do capital, apoiaram-se mutuamente e se fortaleceram, constituindo, até mesmo, impulso motivacional interno para a expansão do sistema em escala progressivamente mais ampliada. Ilustra o autor com o exemplo da produção, que ao defrontar com uma barreira de crescimento, supera-a pela expansão do consumo, e vice-versa. Assim, as limitações imediatas de cada dimensão interna não somente eram superadas graças à interação sistêmica entre elas, mas também usadas como alavancas para potencializar o poder de autopropulsão do capital.

Não é mais o caso, todavia, com a emergência, desde meados da década de 1960, da rastejante mas firme crise estrutural do capital, a qual, segundo Mészáros, emana daquelas três dimensões retro citadas, que, desde o início, constituíram uma unidade contraditória. Essa conflituosidade se constata, por exemplo, ao se observar que a esfera da troca subjuga a da produção, pois, sem a realização da mais-valia produzida, não existe a acumulação de capital. A crise se acirra quando os interesses de cada uma deixam de coincidir com os das demais, passando as contradições entre elas a se tornarem "cumulativas e, portanto, estruturais, trazendo junto a elas um perigoso bloqueio ao complexo mecanismo de deslocamento das contradições." (MÉSZÁROS, 2011b, p. 800). Trata-se, agora, não mais de meras "disfunções", mas de bloqueios na estrutura de funcionamento do próprio sistema, que colocam em risco sua existência como tal. Daí a natureza estrutural da crise.

Em que pese a pertinência e a consistência do modelo teórico construído pelo estudioso húngaro, a apreensão mais exata possível dos determinantes da natureza estrutural da crise que acomete o sistema do capital, desde meados da década de 1960, torna-se 
sobremaneira facilitada com o estudo imanente dos três volumes de $O$ Capital, o que, na verdade, foi precisamente a tarefa empreendida por Mészáros como etapa fundamental de seu ambicioso projeto de "escrever O Capital do século XX" e concretizar, assim, o sonho de seu mestre György Lukács, inúmeras vezes por este mencionado.

$\mathrm{Na}$ próxima seção, procurar-se-á recuperar a configuração histórica, política e econômica pós-Segunda Grande Guerra, que ficou conhecida como fordismo, a qual, em seus breves "trinta anos gloriosos", lançou as bases da atual crise estrutural que, desde os anos 1960, atinge o mundo capitalista.

\section{O esgotamento do regime de acumulação fordista como expressão fenomênica da crise estrutural do capital}

A relativa estabilidade e o crescimento socioeconômico proporcionados pelo binômio fordismo/keynesianismo ${ }^{6}$ nos países de capitalismo avançado perdurou do pós-Segunda Guerra Mundial até aproximadamente os primeiros anos da década de 1970. A partir de então, conforme Harvey (2008), as economias desses países são atravessadas por uma complexa metamorfose, a qual lança os fundamentos da ordem neoliberal que se consolidou a partir da década seguinte. Basicamente, de acordo com aquele autor, pode-se resumir a configuração sociopolítica e econômica do regime de acumulação fordista nos seguintes termos.

Por todo aquele período, estabeleceu-se um pacto entre Estado, capital e trabalho, calcado na expansão contínua da produção, com significativa participação dos trabalhadores nos resultados financeiros das empresas mediante salários relativamente elevados, em patamares nunca antes praticados, tendo como contrapartida o arrefecimento, por parte dessa classe social, da postura de combate ao capital e a cooptação das poderosas organizações sindicais atuantes naquelas nações. De sua parte, o Estado entrava com uma ampla gama de direitos sociais à disposição dos trabalhadores (educação, saúde, planos de previdência e aposentadoria), financiados mediante taxação sobre os lucros auferidos pelo capital, estes

\footnotetext{
${ }^{6}$ Fordismo: neologismo cunhado por Antonio Gramsci, e notabilizado em seu Caderno 22 dos Cadernos do Cárcere (GRAMSCI, 2001), intitulado Americanismo e Fordismo, Por esse termo, Gramsci pretendia aludir ao sistema de produção em massa implantado pelo empresário estadunidense Henry Ford, a partir da segunda década do século XX, nos Estados Unidos da América, caracterizado pela extrema racionalização capitalista, baseada em inovações técnicas e organizacionais, da produção em grande escala de bens destinados ao consumo final de massa. Keynesianismo: Vertente teórica da ciência econômica, tributária das ideias do economista inglês John Maynard Keynes (1883-1946), que advoga a intervenção saneadora e estimuladora do Estado na política econômica nacional, médiante instrumentos de política fiscal (preponderantemente), creditícia e monetária.
} 
sempre ascendentes, tendo em vista a contínua expansão internacional de seus mercados. Segundo Harvey,

O Estado, por sua vez, assumia uma variedade de obrigações. Na medida em que a produção de massa, que envolvia pesados investimentos em capital fixo, requeria condições de demanda relativamente estáveis para ser lucrativa, o Estado se esforçava por controlar ciclos econômicos com uma combinação apropriada de políticas físcais e monetárias no período pós-guerra. Essas políticas eram dirigidas para as áreas de investimento público - em setores como o transporte, os equipamentos públicos etc. - vitais para o crescimento da produção e do consumo de massa e que também garantiam um emprego relativamente pleno. Os governos também buscavam fornecer um forte complemento ao salário social com gastos de seguridade social, assistência médica, educação, habitação etc. [...]. (HARVEY, 2008, p. 129).

Fica difícil não perceber que a legitimidade do Estado (para os outros dois partícipes do pacto), nesse arranjo, provinha de sua capacidade de continuar suprindo, à base social do sistema, aqueles serviços essenciais básicos, aliviando, para o capital, seus custos com mão de obra, contribuindo, dessa forma, para baratear o valor da força de trabalho e, consequentemente, aumentar a taxa de exploração (taxa de mais-valia) dessa. A viabilidade desse esquema dependia, assim, da capacidade fiscal do Estado, a qual, por sua vez, nutria-se do desempenho econômico-financeiro dos grandes conglomerados empresariais multinacionais.

A forte concentração de capitais nos imensos conglomerados monopolistas estadunidenses atenuou sensivelmente a acirrada competição intercapitalista, aproveitando-se aquelas corporações dos programas de reconstrução dos países europeus aliados, que tiveram vastas áreas de seus territórios destruídas na Segunda Grande Guerra. Resolvia-se, assim, momentaneamente, o problema da capacidade de produção excessiva da economia ianque, enquanto se construíam mercados globais para consumo de seus produtos e fornecimento de matéria-prima à sua indústria.

Os Estados Unidos, não somente pela pujança de sua economia, mas também por ter, com o acordo de Bretton Woods, transformado o dólar em moeda-reserva mundial, hegemonizava todo esse processo, vinculando o desenvolvimento econômico do mundo capitalista, sob os auspícios do fordismo, à sua política fiscal e monetária. O capital parecia imbatível e inabalável, em sua saga de incorporar cada vez mais nações, até então, incólumes à sua "missão civilizadora", seja pelo comércio internacional, nas bases de desfavorabilidade dos termos de troca para as nações pobres, seja pelo próprio investimento estrangeiro direto (IED) nos países que apresentavam taxa de mais-valia atraente aos grandes monopólios. Nas palavras de Harvey: 
[...] o núcleo essencial do regime fordista manteve-se firme ao menos até 1973, e, no processo, até conseguiu manter a expansão do período pós-guerra - que favorecia o trabalho sindicalizado e, em alguma medida, estendia os 'benefícios' da produção e do consumo de massa de modo significativo - intacta. Os padrões materiais de vida para a massa da população nos países capitalistas avançados se elevaram e um ambiente relativamente estável para os lucros corporativos prevalecia. (HARVEY, 2008, p. 134).

Todavia, o arranjo se fundava na crescente e ilimitada expansão da produção, o que é incompatível com a real dinâmica da reprodução sociometabólica do capital, que tem, nas crises de superprodução e de realização da mais-valia, componentes intrínsecos ao próprio sistema. Ademais, a rigidez inerente ao fordismo, presente nos investimentos de capital fixo de larga escala e de longo prazo em sistemas de produção em massa que impediam suficiente flexibilidade de planejamento e pressupunham crescimento estável em mercados de consumo constantes, comprometia consideravelmente o funcionamento do sistema. Esse fator contribuía sobremaneira para a diminuição de desempenho econômico e de produtividade das empresas, com a consequente redução da capacidade fiscal do Estado para continuar sustentando a política de bem-estar social naquelas sociedades.

Importa destacar um relevante elemento dessa conjuntura, a saber, o reaparecimento da contestação radical dos trabalhadores às suas condições de aviltamento não somente no processo de trabalho capitalista, mas também na própria sociedade industrial, desencadeando violentas manifestações de massas, das quais as célebres de maio de 1968 tornaram-se as mais emblemáticas.

Os acontecimentos de maio de 1968 na França pegaram de surpresa os teóricos sociais de então, pelo caráter abrangente da base social (não apenas operária) daquele movimento, que foi cronologicamente seguido por greves obreiras, não significando isso que aqueles tenham sido a causa destas, mas evidenciando a interação e inter-relação entre as diversas dimensões do complexo social na dinâmica da luta de classes. Não obstante, impõe-se, a bem da mais fiel possível compreensão da natureza e dos desdobramentos sociopolíticos e históricos daqueles acontecimentos, que se apreenda o papel decisivo do operariado.

No intervalo compreendido entre os meses de maio e junho de 1968, um contingente superior a dez milhões de trabalhadores participou da maior greve da história do movimento obreiro francês, contemplando a maioria dos setores da economia e do aparelho do Estado, como bem ilustra Maurice Grimaud, ex-chefe de polícia de Paris, em entrevista de 1988:

O verdadeiro perigo começou quando os operários entraram em cena. Primeiramente, no dia 13 de maio, uma grande manifestação de solidariedade depois da noite das barricadas e depois, nos dias seguintes, quando os operários mais jovens, sem consultar os seus sindicatos, decidiram seguir os estudantes. Em 16 e 17 de maio, quando as grandes forças da CGT e CFDT [federação de sindicatos], entendendo que sua credibilidade estava muito abalada, chamam a generalização da

Em Debat: Rev. Dig., ISSNe 1980-3532, Florianópolis, n. 10, p. 105-120, jul-dez, 2013. 
greve. Foi nesse momento que apareceu claramente a fragilidade do Estado. A polícia podia dispersar atos, destruir dez ou vinte barricadas, mas não podia controlar cem ou quinhentas fábricas, oficinas, lojas, bancos e estações de trem. Muito menos poderia trazê-los de volta ao trabalho.

Importa salientar que o espírito do maio de 1968 transcendeu o espaço territorial francês, com explosões de insatisfação de trabalhadores e estudantes nos principais países da Europa Ocidental e mesmo na periferia do capitalismo, como foi o caso no México em dois de maio, quando mais de duzentos estudantes foram assassinados pelo aparelho repressor daquele Estado na Praça das Três Culturas, na capital federal. Nos EUA, as manifestações ocorrem no contexto da ferrenha oposição popular à invasão do Vietnã.

A luta de classes agudiza-se e explicita-se acentuadamente, pondo fim ao "pacto" que domesticou a classe trabalhadora por mais de vinte anos, para dissabor e preocupação do capital, já às voltas com os problemas mencionados.

Harvey (2008) aponta que, em meados da década de 1960, a recuperação pós-Segunda Guerra das economias japonesa e dos maiores países da Europa Ocidental já estava consolidada, e começava a despontar capacidade excessiva interna em suas indústrias, o que levava esses Estados a incrementarem sensivelmente a concorrência intercapitalista por novos mercados, no exterior, complicando mais ainda a situação da economia estadunidense. Esta vinha sofrendo desaquecimento progressivo em sua demanda efetiva, por conta do crescente desemprego em razão do aumento da taxa de composição orgânica do capital, decorrente do processo de aguda racionalização fordista em suas empresas. Brenner situa o processo nos seguintes termos:

Essas economias de desenvolvimento tardio produziam os mesmos bens que já
produziam as economias mais maduras, todavia com preços mais competitivos. O
resultado era um excesso de oferta em relação à demanda numa indústria após a
outra, e isso implicava preços e, por conseguinte, lucros baixos. As empresas que
sofriam essas reduções de lucros, mesmo assim, não abandonavam facilmente esses
setores industriais em direção a outros mais rentáveis. Tentavam conservar sua fatia
de mercado recorrendo à capacidade de inovação, aumentando o investimento em
novas tecnologias, o que, na verdade, piorava mais ainda a sobrecapacidade
daquelas economias. Por causa da queda de sua taxa de lucro, os capitalistas
obtinham mais-valia cada vez em menor quantidade em relação ao seu investimento.
Daí que não tiveram mais outra opção a não ser diminuir o investimento em
equipamentos [o que leva à diminuição da demanda agregada no Departamento I da
economia] e força de trabalho [idem, no Departamento II]; [...]. Contudo, as
consequências de todos esses cortes de gastos foi um problema muito mais grave, a
queda da demanda agregada, a longo prazo. A persistente debilidade da demanda
agregada é a origem imediata de debilidade a longo prazo da economia.
(BRENNER, 2009, p. 20).

A partir do início da década de 1970, a fragilidade das bases constitutivas desse padrão de acumulação (sem falar nas próprias contradições inerentes ao MCP) se manifesta com a

\footnotetext{
${ }^{7}$ Disponível em: < http://www.ler-qi.org/Franca-maio-de-1968-a-promessa-da-revolucao $>$, acesso em 9/8/2014.

Em Debat: Rev. Dig., ISSNe 1980-3532, Florianópolis, n. 10, p. 105-120, jul-dez, 2013.
} 
recessão que atingiu a maioria das economias centrais capitalistas mundiais, da qual a eclosão da "crise do petróleo", em 1973, é apenas sua manifestação mais visível ${ }^{8}$. Por sua vez, Brenner (2009) chama a atenção para a profunda e duradoura queda das taxas de rendimento em inversões de capital e de lucros, desde finais dos anos 1960, das quais aponta como causa principal, apesar de não a única, uma persistente tendência à sobre-capacidade de produção nas indústrias manufatureiras mundiais.

A própria crise do fordismo e do keynesianismo, em si, constitui expressão fenomênica da crise estrutural que atinge o sistema do capital, em sua incapacidade de remunerar satisfatoriamente as enormes massas de capitais que se avolumam, tendo em vista as dificuldades de realização da mais-valia produzida, por conta da deterioração do nível de remuneração da classe trabalhadora.

Dentre os mais salientes sintomas do quadro crítico que àquela altura é acometido o capitalismo, é possível assinalar: a) queda da taxa de lucro, fartamente documentada por Mandel (1982, 1990), para as economias dos Estados Unidos, Japão, Suécia, Inglaterra, França e Alemanha; b) o esgotamento do padrão de acumulação taylorista/fordista de produção, dado pela incapacidade de responder à retração do consumo que se acentuava, como consequência do desemprego estrutural que então se iniciava; c) hipertrofia da esfera financeira, que ganhava relativa autonomia frente aos capitais produtivos, o que já era expressão da própria crise estrutural do capital e seu sistema de produção, que não mais conseguia (e nem consegue, na contemporaneidade), na esfera produtiva, extrair mais-valia suficiente para remunerar os capitais ávidos por remuneração compatíveis com suas expectativas de taxas de retorno; d) a crise do Welfare State e dos seus mecanismos de funcionamento, conformando a crise fiscal do Estado capitalista, e a necessidade de retração dos gastos públicos e sua transferência para o capital privado; e) incremento acentuado das privatizações, desregulamentações e a flexibilização do processo produtivo, dos mercados e da força de trabalho (ANTUNES, 2009).

A crise do fordismo pode ser interpretada, até certo ponto, como o esgotamento das opções para lidar com a tendência de superacumulação. Harvey (2008) lembra que tal tendência é ineliminável no capitalismo, e que resta apenas, nos marcos desse modo de produção, administrar essa característica constitutiva do sistema, de forma a não ameaçar sua

\footnotetext{
${ }^{8}$ Mandel (1990, p. 9) salienta a peculiaridade da crise, ao assinalar que, "Entre 1974 e 1975, a economia capitalista internacional conheceu a sua primeira recessão generalizada desde a II Guerra Mundial, sendo a única, até então, a golpear simultaneamente todas as grandes potências imperialistas". Por outro lado, ressalta que a referida recessão "é a conclusão de uma fase típica de queda da taxa média de lucros", portanto, "uma crise clássica de superprodução" (MANDEL, 1990, p. 23).
} 
ordem social. Por conta disso, a burguesia deve optar entre as seguintes alternativas, para conseguir manejar as contradições do MCP dentro de seus marcos internos: a) desvalorização de capital, expressa na queda dos valores de mercadorias, de capacidade produtiva, do dinheiro, chegando até a, caso necessário, destruição direta de ativos; b) controle macroeconômico, por intermédio de algum sistema de regulação, no que o regime fordista-keynesiano constituiu seu melhor paradigma; e c) absorção da superacumulação por meio do deslocamento espacial e temporal.

A terceira alternativa prevaleceu nos anos finais do regime fordista-keynesiano, na estratégia adotada com vistas a atenuar a superacumulação que marcou o longo período de expansão do pós-Segunda Guerra. A lógica consistia em deslocar para frente, espacial e temporalmente, contradições imanentes e insolúveis do sistema do capital, de modo a dar sobrevida ao sistema.

Do ponto de vista do deslocamento espacial, ocorreu conforme mencionado anteriormente, quando se destacou a recuperação das economias japonesa e dos maiores países da Europa Ocidental, que, juntamente aos países de industrialização tardia, passaram a concorrer com os Estados Unidos por novos mercados externos para seus produtos e por fontes de matérias-primas fundamentais para suas indústrias.

$\mathrm{Na}$ perspectiva do deslocamento temporal, a dificuldade de realização da mais-valia era contornada mediante a "ajuda estranha" do Estado, o qual procurava absorver o excedente de capital e de trabalho de um determinado ano em investimentos públicos e privados de longo prazo em obras de infraestrutura física (estradas, por exemplo), de logística (portos), sociais (escolas, hospitais), etc. Dessa forma, os superávits anteriores, encalhados, eram absorvidos no presente, para devolver à sociedade seu equivalente em valor durante um longo período de tempo futuro, quando aqueles investimentos começassem a apresentar retorno compatível com os valores neles investidos. Resolvia, assim, o problema imediato dos capitalistas, agravando a situação fiscal do Estado, que, para financiar suas dívidas, chegou ao ponto de ter que imprimir dinheiro sem lastro real, gerando um surto inflacionário que corroeu o valor das dívidas passadas, com repercussões políticas.

Por volta de 1973, segundo Harvey, esses mecanismos esgotaram sua capacidade de atenuação das contradições subjacentes do MCP, e

[...] Parecia não haver opção além do retorno à desvalorização [...] como meio primário de lidar com a tendência de superacumulação. Isto é, a não ser que algum outro regime superior de produção capitalista, capaz de garantir uma sólida base para uma maior acumulação em escala global, pudesse ser criado. (HARVEY, 2008, p. 174). 
A solução encontrada pelo capital foi a emergência de um novo regime de acumulação, o qual pareceu se enquadrar como uma recombinação simples das duas estratégias de busca de lucro (mais-valia) descobertas por Marx, a mais-valia absoluta e a relativa. Com base na primeira, passa a ocorrer, a partir de então, a transferência do capital corporativo de regiões de altos salários para regiões de baixos salários, criando o "fordismo periférico". Pela segunda estratégia, baseada na mais-valia relativa, a mudança organizacional e tecnológica é posta em ação para gerar lucros temporários para firmas inovadoras e lucros mais generalizados com a redução dos custos dos bens consumidos pelas famílias trabalhadoras, que definem o valor do trabalho.

No bojo dessa reação do capital, com vistas a recuperar níveis anteriores de lucratividade e crescimento econômico, sobreveio um profundo processo de reestruturação da produção e do trabalho e, não menos relevante, de seu sistema ideológico e político de dominação, que ficou conhecido como "regime de acumulação flexível" (HARVEY, 2008, p. 140), “capitalismo flexível” (SENNETT, 2004, p. 9, 2006, p. 41-49) e muitas outras expressões equivalentes, cunhadas por diversos teóricos que analisaram a nova quadra capitalista que emergiu a partir do último quartel do século XX. ${ }^{9}$

Longe de consubstanciar uma solução minimamente consistente da crise estrutural do capital que debelasse as contradições sistêmicas do próprio modo de produção, o recurso ao neoliberalismo constituiu, naquelas circunstâncias, o único arranjo possível, nos marcos do modo de produção em vigor, capaz de manter e por certo tempo até mesmo incrementar o ritmo e a intensidade da acumulação de capital, sem comprometer as estruturas de poder econômico e geopolítico globalmente vigentes, mesmo que a partir de uma estratégia débil, a médio/longo prazo, a saber, a opção rentista, que privilegia a extração de mais-valia por intermédio de mecanismos meramente financeiros, sem o devido lastro na produção real da economia.

Como evidência do iminente esgotamento dessa via, pode-se apontar os graves efeitos da mais recente grande crise cíclica do capitalismo, a "crise de 2008", que tem castigado indistintamente países desenvolvidos e subdesenvolvidos ${ }^{10}$, processo no qual a

\footnotetext{
${ }^{9}$ Trata-se do regime de acumulação flexível, o qual emergiu no bojo da reestruturação produtiva do capital, que constitui processo analisado por este pesquisador no segundo capitulo de sua dissertação de mestrado, ora em processo de conclusão.

${ }^{10}$ Anualmente, pelo menos quinze por cento da população dos EUA precisa do auxílio de programas de transferência de renda, como o Bolsa Família brasileiro, para não passar fome. Somente em Nova York, cinco mil pessoas recebem um benefício para viverem afastadas da fome. (http://www.oeconomista.com.br/criseaumenta-desigualdade-nos-eua-e-destroi-o-sonho-americano acesso em 09 set 2014) Segundo dados do governo, mais de quarenta e nove milhões de norte-americanos estavam em situação de pobreza em 2010 e, nesse período, o número de famílias que dependia de ajuda alimentar subiu para mais de treze milhões.
} 
macroestrutura oligopólica financeira internacional tem imposto a essas sociedades medidas de austeridade que já se refletem em aviltante regressão dos padrões civilizacionais daquelas formações sociais.

\section{REFERÊNCIAS}

ANTUNES, Ricardo. Os sentidos do trabalho: ensaio sobre a afirmação e a negação do trabalho. São Paulo: Boitempo, 2009.

BRENNER, Robert. Un análisis histórico-económico clásico de la actual crisis. 2009. In: Alvarez, Jairo Estrada (Org.). Crisis capitalista: economia, política y movimiento. Bogotá: Espacio Crítico, 2009. p. 19-36.

GRAMSCI, Antonio. Cadernos do cárcere: temas de cultura. Ação católica. Americanismo e fordismo. Rio de Janeiro: Civilização Brasileira, 2001. v. 4.

HARVEY, David. A condição pós-moderna. São Paulo: Loyola, 2008.

HAYEK, Friedrich. O caminho da servidão. São Paulo: Instituto Ludwig von Mises Brasil, 2010.

MANDEL, Ernest. A crise do capital: os fatos e sua interpretação marxista. São Paulo: Ed. Ensaios, 1990.

\section{. O capitalismo tardio. São Paulo: Abril Cultural, 1982.}

MARX, Karl. O capital. Rio de Janeiro: Civilização Brasileira, 2008. Livro 3, v. 4.

MÉSZÁROS, Istvam. A crise estrutural do capital. Outubro-Revista do Instituto de Estudos Socialistas, São Paulo, n. 4, p. 07-15, 2000.

A crise estrutural do capital. São Paulo: Boitempo, 2011a.

Para além do capital: rumo a uma teoria da transição. São Paulo: Boitempo, 2011b.

(http://economia.uol.com.br/ultimas-noticias/reuters/2011/12/15/pobreza-e-fome-aumentam-em-cidades-doseua-indica-estudo.jhtm - acesso em 09 set 2014). Na Europa, o quadro é o mesmo. 
SENNETT, Richard. A corrosão do caráter: consequências pessoais do trabalho no novo capitalismo. Rio de Janeiro: Record, 2004.

A cultura do novo capitalismo. Rio de Janeiro: Record, 2006. 